\title{
Exercise Training: A Hero that Can Fight two Pandemics at Once
}

\author{
Renata Rodrigues Teixeira de Castro, ${ }^{1,2,3(0)}$ João Giffoni da Silveira Neto, ${ }^{1,3}$ Roberta Rodrigues Teixeira de Castro ${ }^{1,3(0)}$ \\ Universidade lguaçu, ${ }^{\prime}$ Nova lguaçu, RJ - Brazil \\ Hospital Naval Marcílio Dias, Comando da Marinha, ${ }^{2}$ Rio de Janeiro, RJ - Brazil \\ Cardiologia do Esporte, ${ }^{3}$ Rio de Janeiro, $R J$ - Brazil
}

On March $11^{\text {th }}, 2020$, the World Health Organization (WHO) declared that the new COVID-19 outbreak was a public health emergency of pandemic proportions. At that time, there were more than 118,000 infected patients in 114 countries and 4,291 people had lost their lives. While daily statistics show increases in the number of deceased and infected people, and despite all the efforts of scientists all over the world, governments and healthcare professionals are facing the challenge of taking decisions driven on data that is new, incomplete or even unavailable..$^{1-3}$

To prevent virus spreading, some governments put major cities in lockdown and others promoted social distancing, banning public events and shutting down public places, including parks and beaches. Gyms and other training facilities were also closed, leaving people with no secure place to exercise. At first glance, it may seem that there is no other option, but to stay home without exercising. Nevertheless, not exercising is not the only choice for people practicing social isolation. It is, in fact, a very unhealthy choice that should not be considered.

\section{The sedentarism pandemic}

The WHO recommends that adults aged 18 years and older should accumulate at least 150 minutes of moderate-intensity aerobic activity, 75 minutes of vigorous-intensity aerobic activity, or a combination of both per week. ${ }^{4}$ People who do not meet these

\section{Keywords}

COVID-19; Coronavirus, Communicable Diseases, Emerging; Pandemics; Exercise; Motor Activity/methods; Comorbidity; Social Isolation; Breathing Exercises/methods. requirements are considered sedentary. The health benefits of physical exercise include lower risks of cardiovascular disease, hypertension, diabetes, obesity, dementia and breast and colon cancer. ${ }^{5-9}$ Despite all these benefits, sedentarism is a pandemic, affecting $27.5 \%$ of people globally. ${ }^{10}$

Sedentarism increases the risk of the world's major non-communicable diseases. I-Min Lee et al., ${ }^{11}$ estimated that physical inactivity is responsible for $6 \%$ of the burden of coronary artery disease, $7 \%$ of type 2 diabetes, $10 \%$ of breast cancer and colon cancers. Thus, inactivity is considered responsible for $9 \%$ of premature mortality, globally. Actually, sedentarism kills more people annually than the COVID-19 infection.

Comorbidities and prognosis in patients with COVID-19

Yang et al., ${ }^{12}$ described that, in Chinese patients infected with COVID-19, hypertension was the most prevalent comorbidity (17 $\pm 7 \%$ ), followed by diabetes $(8 \pm 6 \%)$ and cardiovascular diseases $(5 \pm 4 \%)$. Another meta-analysis confirmed that these comorbidities were associated with poor prognosis. Data about exercise habits in patients infected by COVID-19 is yet not available. Nevertheless, it is clear that these comorbidities would be less prevalent if minimal WHO's exercise requirements were globally met. ${ }^{4}$

\section{Exercise training can help fight viral infections}

Exercise training is considered effective in primary prevention and in the treatment of most chronic diseases, ${ }^{11,13-16}$ especially the most prevalent ones, that confers worst prognosis in COVID infections. Thus, physical training itself may prevent deaths during this pandemic. 
Physical training is also known to improve immune response. Despite the concerns of some athletes about the side effects of vaccination, high exercise intensity and frequency enhance vaccine-responses in elite athletes. ${ }^{17}$ This is also true in older people where immunoglobulins concentrations after vaccinations are greater in cardiovascular-trained individuals than in control ones. ${ }^{17-22}$

Despite the promising effects of exercise training on the immune system, exercise stress may be associated with an increased risk for upper respiratory tract infection. ${ }^{23}$ Acute bouts of heavy exercise and chronic intensive exercise, as usually performed by long-distance runners, compromise host defenses and increase the incidence of upper respiratory tract infections..$^{24,25}$ In athletes under heavy training both innate and acquired immunity are often observed to decrease, typically $15-25 \% .{ }^{26}$

It is true that exercise can modulate many immune system components, altering the susceptibility to infections, which means that exercise training may increase or reduce the susceptibility to infections. Although it may seem paradoxical, this assertive is true, and quite straightforward. A large study ${ }^{27}$ about the Hong Kong flu outbreak in 1998 concluded that mild to moderate exercise, performed three to five times per week reduced the risk of mortality, while people who did not exercise or who exercised too much were at greatest risk of death. Thus, the missing piece of the survival puzzle during pandemic is not exercise itself, but its detailed prescription.

\section{Exercise prescription during the COVID pandemic}

Physicians learn how to prescribe various drugs. Although exercise is beneficial for the treatment of several diseases, exercise prescription is not taught to medicine students or residents. ${ }^{28,29}$ As any other medication, exercise training needs the right dosing to achieve the desired effects. The American College of Sports Medicine has introduced the FITT-VP principle as a mnemonic with all the points that must me described in exercise prescription: Frequency, Intensity, Type, Time, Volume and Progression. ${ }^{6}$

Social restrictions, correctly imposed during the COVID-19 pandemic, is certainly disrupting routine daily activities of people globally. ${ }^{30}$ Still, there are exercises that can be safely done at home. Considering the previous discussion on the minimal training volume ${ }^{4}$ for health, recommended by the $\mathrm{WHO}$, and the embedded risks of immunity reduction due to high intensity training, the following principles can guide home-based exercise while at social isolation.

\section{First do no harm}

This principle of the Hippocratic Oath applies here. Exercise has its risks, which are not easily gathered remotely. Before starting exercising by themselves, patients must be sure that all questions in the PAR-Q questionnaire $^{31-33}$ are negative. In addition, it is not recommended to exercise if the patient is experiencing flu symptoms, sore throat, body aches, shortness of breath, fatigue cough or fever. Patients with any positive answer to the PAR-Q questionnaire or presenting any of these symptoms should seek medical advice before start exercising.

\section{Frequency}

Guidelines suggest that sedentary people start with aerobic exercise 3 to 5 times per week and that resistance training is done 2 to 3 times per week. Flexibility and mobility exercises can be done on most days.

\section{Intensity}

During the pandemics, one should not engage in high intensity exercise. That being said, it is important to know how to evaluate exercise intensity. There are various ways to do that, but some, such as anaerobic threshold, maximal oxygen volume uptake and real maximal heart rate, require exercise tests not available during the pandemic. Although the maximum heart rate calculation (Maximum heart rate $=220$-age) presents errors, ${ }^{34}$ it is probably the most feasible way to analyze one's maximal heart rate when maximal exercise tests cannot be done.

During light intensity exercise, heart rate is kept below $45 \%$ of maximum heart rate. The heart rate during moderate intensity exercise is kept between 64 and $76 \%$ of maximum heart rate. Thus, during the pandemic, exercise heart rate should not be higher than $77 \%$ of maximum heart rate (vigorous exercise).

Resistance exercise prescription usually considers percentages of repetition maximum for each exercise. ${ }^{6,35}$. As repetition maximum tests uses equipment that are not available at home, some adaptations need to be done. Strength exercises that 
only requires body weight, as pushups, sit-ups and lunges can be done. Resistance bands are also good options. If more resistance is needed, books, food packages and other objects can all be used as weights for training.

\section{Time}

Exercise duration depends on individual aerobic capacity, but sets of 30 to 50 minutes are recommended.

\section{Type}

Multicomponent exercise programs including aerobic, resistance, flexibility and balance training exercises are recommended ${ }^{4}$.

\section{Volume}

Guidelines recommend at least 150 minutes of aerobic exercise and two resistance training sessions per week. My personal view, considering the risks of immune depletion related to high volume training, is that people who used to exercise before the pandemic should try to keep the same training volume. People who were sedentary should try to adhere to the minimal requirements.

\section{Progression}

It is time to keep fit, not to pursue increases in fitness.

\section{References}

1. Calisher C, Carroll D, Colwell R, Corley RB, Daszak P, Drosten C, et al. Statement in support of the scientists, public health professionals, and medical professionals of China combatting COVID-19. Lancet. 2020;395(10226):e42-e43.

2. Li H, Zhou Y, Zhang M, Wang H, Zhao Q, Liu J. Updated approaches against SARS-CoV-2. Antimicrob Agents Chemother. 2020.

3. Lippi G, Plebani M. The critical role of laboratory medicine during coronavirus disease 2019 (COVID-19) and other viral outbreaks. Clin Chem Lab Med. 2020.

4. World Health Organization. (WHO. Global recommendation on physical activity for health. Geneva: 2010.

5. Fletcher GF, Ades PA, Kligfield P, Arena R, Balady GJ, Bittner VA, et al. Exercise standards for testing and training: a scientific statement from the American Heart Association. Circulation. 2013;128(8):873-934.

6. Garber CE, Blissmer B, Deschenes MR, Franklin BA, Lamonte MJ, Lee IM, et al. American College of Sports Medicine position stand. Quantity and quality of exercise for developing and maintaining cardiorespiratory, musculoskeletal, and neuromotor fitness in apparently healthy adults: guidance for prescribing exercise. Med Sci Sports Exerc. 2011;43(7):1334-59.

7. Sales AR, Silva BM, Neves FJ, Rocha NG, Medeiros RF, Castro $R R$, et al. Diet and exercise training reduce blood pressure and improve autonomic modulation in women with prehypertension. Eur J Appl Physiol. 2012;112(9):3369-78.

\section{Conclusion}

Government measures that restrict people at home during the COVID-19 pandemic do not need to encourage the wider spread of the sedentarism pandemic. Exercise can fight both public health problems, as long as it is adequately prescribed. Maintaining regular physical activity at home is pivotal for healthy living during and after the COVID-19 global crisis.

\section{Author contributions}

Conception and design of the research: Castro RRT. Acquisition od data: Castro RRT. Analysis and interpretation of the data: Castro RRT. Writing of the manuscript: Castro RRT, Silveira Neto JG, Castro RRT. Critical revision of the manuscript for intellectual content: Castro RRT, Silveira Neto JG, Castro RRT.

\section{Potential Conflict of Interest}

No potential conflict of interest relevant to this article was reported.

\section{Sources of Funding}

There were no external funding sources for this study.

\section{Study Association}

This study is not associated with any graduation program.

8. Taylor RS, Walker S, Smart NA, Piepoli MF, Warren FC, Ciani O, et al. Impact of Exercise Rehabilitation on Exercise Capacity and Qualityof-Life in Heart Failure: Individual Participant Meta-Analysis. J Am Coll Cardiol. 2019;73(12):1430-43.

9. Herdy AH, López-Jiménez F, Terzic CP, Milani M, Stein R, Carvalho $\mathrm{T}$, et al. South American guidelines for cardiovascular disease prevention and rehabilitation. Arq Bras Cardiol. 2014;103(2 Suppl 1):1-31.

10. Guthold R, Stevens GA, Riley LM, Bull FC. Worldwide trends in insufficient physical activity from 2001 to 2016: a pooled analysis of 358 population-based surveys with 1.9 million participants. Lancet Glob Health. 2018;6(10):e1077-e1086.

11. I-Min L, Shiroma E, Lobelo F, Puska P, Blair S, Katzmarzyk P. Impact of Physical Inactivity on the World's Major Non-Communicable Diseases. Lancet. 2012;380:11.

12. Yang J, Zheng Y, Gou X, Pu K, Chen Z, Guo Q, et al. Prevalence of comorbidities in the novel Wuhan coronavirus (COVID-19) infection: a systematic review and meta-analysis. Int J Infect Dis. 2020. [Epub ahead of print]

13. Blair SN, Kohl HW, Paffenbarger RS, Clark DG, Cooper KH, Gibbons LW. Physical fitness and all-cause mortality. A prospective study of healthy men and women. JAMA. 1989;262(17):2395-401.

14. Lavie CJ, Ozemek C, Carbone S, Katzmarzyk PT, Blair SN. Sedentary Behavior, Exercise, and Cardiovascular Health. Circ Res. 2019;124(5):799-815. 
15. Fletcher GF, Landolfo C, Niebauer J, Ozemek C, Arena R, Lavie CJ. Promoting Physical Activity and Exercise: JACC Health Promotion Series. J Am Coll Cardiol. 2018;72(14):1622-39.

16. Ozemek C, Laddu DR, Lavie CJ, Claeys H, Kaminsky LA, Ross R,et al. An Update on the Role of Cardiorespiratory Fitness, Structured Exercise and Lifestyle Physical Activity in Preventing Cardiovascular Disease and Health Risk. Prog Cardiovasc Dis. 2018;61(5-6):484-90.

17. Ledo A, Schub D, Ziller C, Enders M, Stenger T, Gärtner BC, et al. Elite athletes on regular training show more pronounced induction of vaccinespecific T-cells and antibodies after tetravalent influenza vaccination than controls. Brain Behav Immun. 2020;83:135-45.

18. Grant RW, Mariani RA, Vieira VJ, Fleshner M, Smith TP, Keylock KT, et al. Cardiovascular exercise intervention improves the primary antibody response to keyhole limpet hemocyanin (KLH) in previously sedentary older adults. Brain Behav Immun. 2008;22(6):923-32.

19. Schuler PB, Leblanc PA, Marzilli TS. Effect of physical activity on the production of specific antibody in response to the 1998-99 influenza virus vaccine in older adults. J Sports Med Phys Fitness. 2003;43(3):404.

20. de Araújo AL, Silva LC, Fernandes JR, Matias M de S, Boas LS, Machado $\mathrm{CM}$, et al. Elderly men with moderate and intense training lifestyle present sustained higher antibody responses to influenza vaccine. Age (Dordr). 2015;37(6):105

21. Simpson RJ, Kunz H, Agha N, Graff R. Exercise and the Regulation of Immune Functions. Prog Mol Biol Transl Sci. 2015;135:355-80.

22. Smith TP, Kennedy SL, Fleshner M. Influence of age and physical activity on the primary in vivo antibody and T cell-mediated responses in men. J Appl Physiol.1985; (1985). 2004;97(2):491-8.

23. Murphy EA, Davis JM, Carmichael MD, Gangemi JD, Ghaffar A, Mayer EP. Exercise stress increases susceptibility to influenza infection. Brain Behav Immun. 2008;22(8):1152-5.

24. Peters EM, Bateman ED. Ultramarathon running and upper respiratory tract infections. An epidemiological survey. S Afr Med J. 1983;64(15):582-4.
25. Nieman DC, Johanssen LM, Lee JW, Arabatzis K. Infectious episodes in runners before and after the Los Angeles Marathon. J Sports Med Phys Fitness. 1990;30(3):316-28.

26. Walsh NP, Oliver SJ. Exercise, immune function and respiratory infection: An update on the influence of training and environmental stress. Immunol Cell Biol. 2016;94(2):132-9.

27. Wong CM, Lai HK, Ou CQ, Ho SY, Chan KP, Thach TQ, et al Is exercise protective against influenza-associated mortality? PLoS One. 2008;3(5):e2108.

28. Solmundson K, Koehle M, McKenzie D. Are we adequately preparing the next generation of physicians to prescribe exercise as prevention and treatment? Residents express the desire for more training in exercise prescription. Can Med Educ J. 2016;7(2):e79-e96.

29. Windt J, Windt A, Davis J, Petrella R, Khan K. Can a 3-hour educational workshop and the provision of practical tools encourage family physicians to prescribe physical activity as medicine? A pre-post study. BMJ Open. 2015;5(7):e007920.

30. Chen P, Mao L, Nassis GP, Harmer P, Ainsworth BE, Li F. Coronavirus disease (COVID-19): The need to maintain regular physical activity while taking precautions. J Sport Health Sci. 2020;9(2):103-4.

31. Shephard RJ, Cox MH, Simper K. An analysis of "Par-Q" responses in an office population. Can J Public Health. 1981;72(1):37-40.

32. Shephard RJ. PAR-Q, Canadian Home Fitness Test and exercise screening alternatives. Sports Med. 1988;5(3):185-95.

33. Thomas S, Reading J, Shephard RJ. Revision of the Physical Activity Readiness Questionnaire (PAR-Q). Can J Sport Sci. 1992;17(4):338-45.

34. RA R, R L. The surprising history of the "HRmax=220-age"equation. Journal of Exerc Physiol. 2002;5(2):10.

35. Medicine ACoS. American College of Sports Medicine position stand Progression models in resistance training for healthy adults. Med Sci Sports Exerc. 2009;41(3):687-708. 